\title{
Stratospheric ozone chemistry in the Antarctic: what determines the lowest ozone values reached and their recovery?
}

\author{
J.-U. Grooß ${ }^{1}$, K. Brautzsch ${ }^{1}$, R. Pommrich ${ }^{1,2,3}$, S. Solomon ${ }^{4}$, and R. Müller ${ }^{1}$ \\ ${ }^{1}$ Institut für Energie- und Klimaforschung - Stratosphäre (IEK-7), Forschungszentrum Jülich, Jülich, Germany \\ ${ }^{2}$ Laboratoire d'Aérologie, CNRS/INSU, Université de Toulouse, Toulouse, France \\ ${ }^{3}$ Groupe d'étude de l'Atmosphère Météorologique, CNRM-GAME, Météo-France, Toulouse, France \\ ${ }^{4}$ Department of Atmospheric and Oceanic Science, University of Colorado, Boulder, CO, USA
}

Received: 27 July 2011 - Published in Atmos. Chem. Phys. Discuss.: 5 August 2011

Revised: 18 November 2011 - Accepted: 25 November 2011 - Published: 7 December 2011

\begin{abstract}
Balloon-borne observations of ozone from the South Pole Station have been reported to reach ozone mixing ratios below the detection limit of about $10 \mathrm{ppbv}$ at the $70 \mathrm{hPa}$ level by late September. After reaching a minimum, ozone mixing ratios increase to above $1 \mathrm{ppmv}$ on the $70 \mathrm{hPa}$ level by late December. While the basic mechanisms causing the ozone hole have been known for more than $20 \mathrm{yr}$, the detailed chemical processes determining how low the local concentration can fall, and how it recovers from the minimum have not been explored so far. Both of these aspects are investigated here by analysing results from the Chemical Lagrangian Model of the Stratosphere (CLaMS). As ozone falls below about $0.5 \mathrm{ppmv}$, a balance is maintained by gas phase production of both $\mathrm{HCl}$ and $\mathrm{HOCl}$ followed by heterogeneous reaction between these two compounds in these simulations. Thereafter, a very rapid, irreversible chlorine deactivation into $\mathrm{HCl}$ can occur, either when ozone drops to values low enough for gas phase $\mathrm{HCl}$ production to exceed chlorine activation processes or when temperatures increase above the polar stratospheric cloud (PSC) threshold. As a consequence, the timing and mixing ratio of the minimum ozone depends sensitively on model parameters, including the ozone initialisation. The subsequent ozone increase between October and December is linked mainly to photochemical ozone production, caused by oxygen photolysis and by the oxidation of carbon monoxide and methane.
\end{abstract}

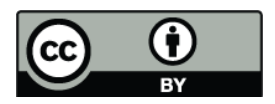

Correspondence to: J.-U. Grooß (j.-u.grooss@fz-juelich.de)

\section{Introduction}

Since the discovery of the ozone hole (Farman et al., 1985), the chemical mechanisms causing ozone depletion have been clarified in increasing detail (e.g., Solomon, 1999; WMO, 2011). These mechanisms lead to an almost complete destruction of ozone at certain altitudes $(\approx 15-20 \mathrm{~km})$ in the Antarctic stratosphere, as observed in measurements by ozone sondes over four decades (Solomon et al., 2005). Figure 1 shows the ozone observations from the South Pole Station at the $70 \mathrm{hPa}$ level. The logarithmic ordinate highlights the massive loss of ozone at this level, with ozone mixing ratios dropping to and even below the approximate instrument detection limit of 10 ppbv (see Vömel and Diaz, 2010) by late September and early October above the South Pole Station. There are some observations that do not display ozone depletion over the South Pole Station, e.g. between late September and early November. These data correspond to times when the polar vortex was not located over the pole, particularly in 2002 .

The graph reveals a lower envelope of the observations that has remained nearly the same in different years since 1990, characterising the chemical decay of ozone to values as low as $10 \mathrm{ppbv}$ around the end of September and increasing again afterwards. While the basic mechanisms for the rapid polar ozone loss are understood (Solomon, 1999), the explanation for the ozone depletion near and below the detection limit of about $10 \mathrm{ppbv}$ have not yet been elucidated, nor has the factor driving the subsequent increase of ozone been identified. Here we use simulations of the Chemical Lagrangian Model of the Stratosphere (CLaMS) to investigate these processes.

Published by Copernicus Publications on behalf of the European Geosciences Union. 


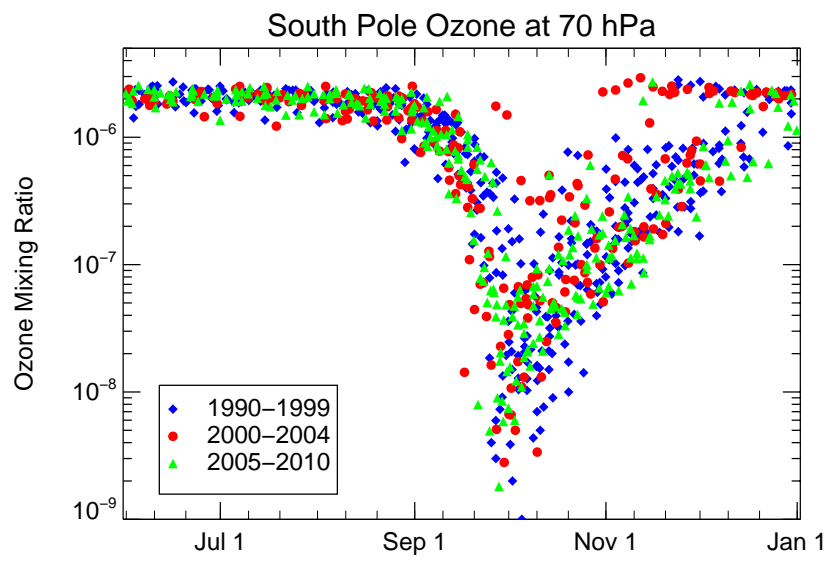

Fig. 1. Ozone sonde observations at $70 \mathrm{hPa}$ from South Pole Station in winter and spring since 1990. Updated from Fig. 7a of Solomon et al. (2005).

\section{Model description}

The simulations presented here are performed with CLaMS (McKenna et al., 2002a,b; Konopka et al., 2004; Grooß et al., 2005a). The model is used in two different modes. In the box-model mode, stratospheric chemistry is calculated for a few representative air parcels along their trajectory whereas the global mode is the Lagrangian 3-dimensional Chemistry Transport Model.

In the box-model mode, the air parcels are defined here by the location and time of ozone soundings in the ozone hole period, from which trajectories are calculated both backward to June and forward to December. Simulations with the CLaMS chemistry module are then performed forward in time using the combination of these two trajectories. The trajectories of the air parcels were calculated using wind and temperature data from the ECMWF operational analysis in a $1^{\circ} \times 1^{\circ}$ resolution. The diabatic descent (or ascent) rates were calculated from a radiation code (Morcrette, 1991; Zhong and Haigh, 1995) for a cloud-free atmosphere based on temperatures from the ECMWF operational analyses and climatological ozone and water vapour profiles (Grooß and Russell, 2005). CLaMS includes options for different solvers to integrate the system of stiff ordinary differential equations describing the chemistry (Carver et al., 1997; McKenna et al., 2002b). The chemical kinetic data are taken from Sander et al. (2006), except for the $\mathrm{Cl}_{2} \mathrm{O}_{2}$ cross sections which are taken from von Hobe et al. (2009), scaled by a factor of 1.48 to match the observation of Lien et al. (2009). The photolysis rates are calculated in spherical geometry (Meier et al., 1982; Becker et al., 2000) for every hour using a climatological ozone profile for ozone hole conditions from HALOE measurements (Grooß and Russell, 2005). Heterogeneous chemistry is calculated on ice, nitric acid trihydrate (NAT), and liquid ternary $\mathrm{H}_{2} \mathrm{O} / \mathrm{H}_{2} \mathrm{SO}_{4} / \mathrm{HNO}_{3}$ particles. The parametrisations of the temperature-dependent uptake coefficient on liquid aerosols are derived from measurements by Hanson (1998) and those on NAT particles are taken from Carslaw and Peter (1997) based on lab measurements derived from Hanson and Ravishankara (1993). NAT formation is assumed to occur at a $\mathrm{HNO}_{3}$ supersaturation of a factor of 10 , corresponding approximately to $3 \mathrm{~K}$ supercooling below $T_{\mathrm{NAT}}$. The NAT particle density is assumed to be $1 \mathrm{~cm}^{-3}$.

In the box-model mode, we employ the solver SVODE (Brown et al., 1989) that does not use the family approximation, which could become invalid at very low ozone mixing ratios. Since no denitrification parametrisation was used in the box-model mode, the chemical consequences of the denitrification were addressed by sensitivity studies. The chemical initialisation for the air parcels in the box-model mode is interpolated from the 3-dimensional CLaMS simulations described below. The results from box-model studies do not include mixing between neighbouring air masses nor denitrification due to sedimentation of $\mathrm{HNO}_{3}$-containing particles. Over the long time span from June to November, a trajectory should certainly not be viewed as representing the exact location of a single air mass. Rather it should be interpreted as one of the possible histories of an air parcel that reaches low ozone mixing ratios. Thus, the results of this trajectorybox-model can be used to investigate the chemical processes around the observed minimum ozone mixing ratios.

The CLaMS 3-D simulations for the ozone hole in the year 2003 were described in detail in a dissertation for a university diploma (Walter, 2005), which focused on the time period up to November 2003. These simulations are continued until the end of December in this work. The CLaMS simulations were initialised on 1 May 2003 using observations from MIPAS-Envisat data for $\mathrm{O}_{3}, \mathrm{~N}_{2} \mathrm{O}$, and $\mathrm{HNO}_{3}$. Correlations with $\mathrm{N}_{2} \mathrm{O}$ were used to initialise $\mathrm{Cl}_{\mathrm{y}}$ (Grooß et al., 2002), $\mathrm{Br}_{y}$ (Grooß et al., 2002)+10\%, and $\mathrm{NO}_{\mathrm{y}}$ Grooß et al. (2005b). The remaining species and the family partitioning were initialised from the Mainz 2-D model (Grooß, 1996). Denitrification by sedimenting NAT particles was simulated with the scheme used for the Arctic winter 2002/2003 (Grooß et al., 2005b). The horizontal resolution of this simulation is $100 \mathrm{~km}$ between 40 and $90^{\circ} \mathrm{S}$. Here, the solver IMPACT was used based on the family concept approximation (Carver and Scott, 2000).

\section{Results}

For investigations of the chemical processes around the ozone minimum in late September, a trajectory was chosen that exactly intersects an observation from the South Pole Station of about $10 \mathrm{ppbv}$ ozone at the pressure level of $70 \mathrm{hPa}$ on 24 September 2003. The box-model simulation was performed along this trajectory for the time period from 1 June to 30 November 2003 . The trajectory stays in the vortex core at an average equivalent latitude of $77^{\circ} \mathrm{S}$ with a standard deviation of $5^{\circ}$. This trajectory should be considered as an 


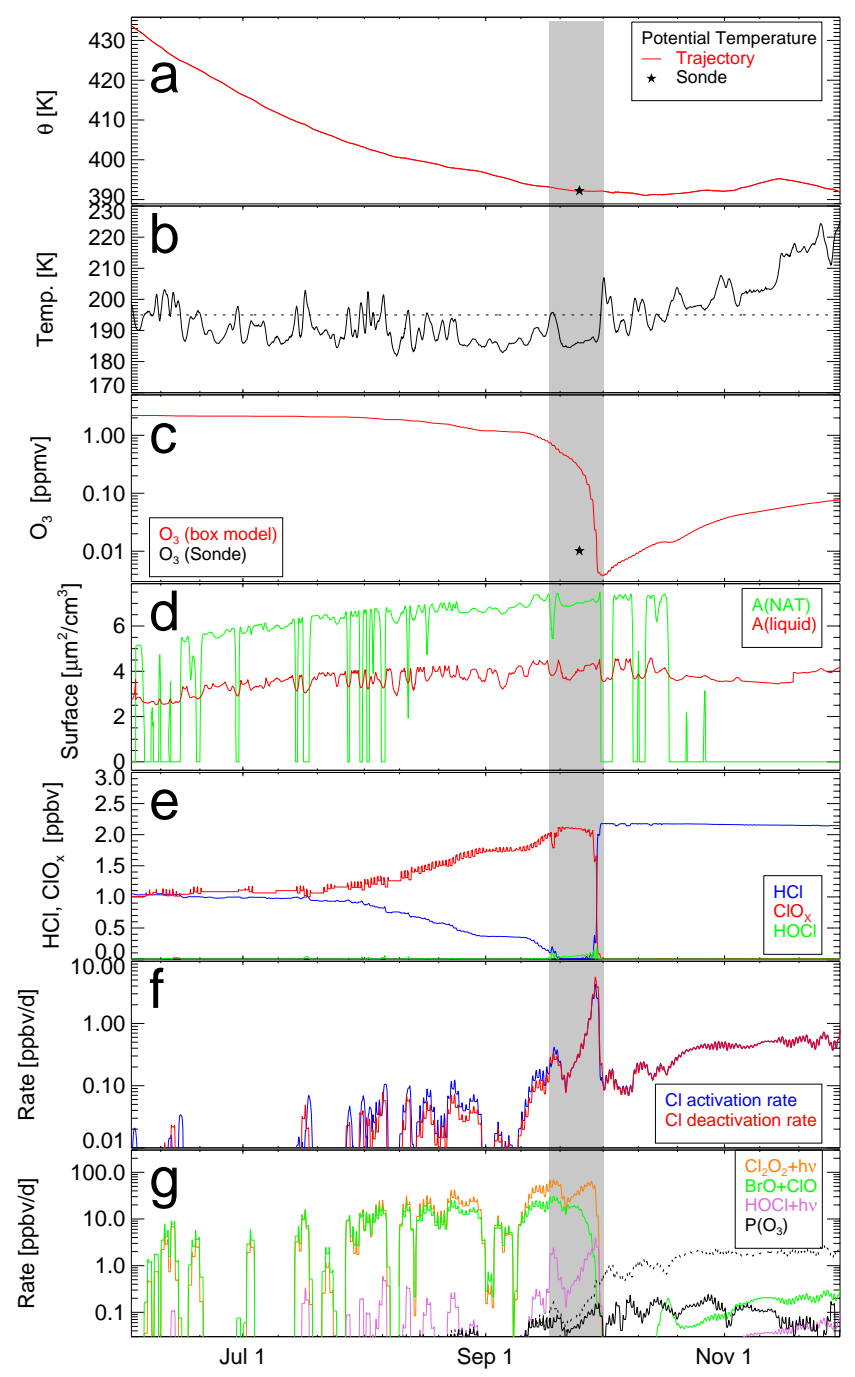

Fig. 2. Box-model simulations along a trajectory passing through the location of the ozone sonde observation of $10 \mathrm{ppbv}$ on $73 \mathrm{hPa}$ on 24 September 2003. The different panels show a time series of the relevant parameters: (a) potential temperature of the air parcel, (b) temperature, (c) ozone (red), (d) surface area density of NAT and liquid aerosol, (e) $\mathrm{ClO}_{\mathrm{x}}, \mathrm{ClONO}_{2}$ and $\mathrm{HCl}$, (f) net rates of chlorine activation and deactivation, $(\mathrm{g})$ rates of catalytic cycles involving ozone including ozone production rate by $\mathrm{O}_{2}+\mathrm{h} v$ (black solid line) and total ozone production rate (black dotted line). For reasons of clarity, the reaction rates (f, $\mathbf{g}$ ) are plotted as $24 \mathrm{~h}$ running averages.

example of the possible development for which the chemistry is investigated in detail. Figure 2 shows the development of the relevant chemical species and reaction rates along the trajectory. Panel a shows the potential temperature of the air parcel with the typical diabatic descent in the polar vortex and panel $b$ shows the temperature along the trajectory. In panel $\mathrm{c}$ we show the simulated ozone mixing ratio. The chosen ozone sonde observation used to determine the trajectory is plotted as a black star symbol. The simulation does reach

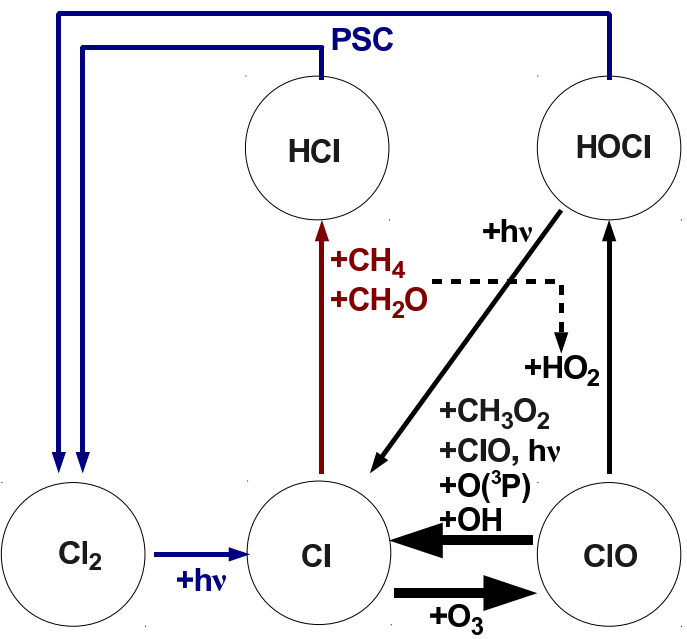

Fig. 3. Schematic of the primary chlorine activation and deactivation reactions occurring in mid-September in these simulations.

ozone mixing ratios as low as those observed, but a a time several days after the ozone sonde observation of $10 \mathrm{ppbv}$.

\subsection{Chlorine deactivation and heterogeneous chemistry}

We first focus on the time period of two weeks before the simulated ozone minimum (grey shaded area in Fig. 2). The simulation shows that the cessation of ozone loss (yielding a minimum near $10 \mathrm{ppbv}$ ) is caused by a very fast deactivation of active chlorine compounds into the reservoir species $\mathrm{HCl}$ on a very short time scale of about a day. Although the temperatures are still low enough for the existence of polar stratospheric clouds (PSCs), chlorine activation does not occur after the ozone minimum because practically all of the inorganic chlorine is in the form of $\mathrm{HCl}$ so that neither $\mathrm{ClONO}_{2}$ nor $\mathrm{HOCl}$ are available as reaction partners for $\mathrm{HCl}$ in heterogeneous chlorine activation processes. Figure 3 shows a simplified schematic of the primary pathways of chlorine activation and chlorine deactivation. The photochemical equilibrium between $\mathrm{Cl}$ and $\mathrm{ClO}$ is indicated by thick black arrows. The main heterogeneous chlorine activation reaction during the period shown by the grey shading is $\mathrm{HOCl}+\mathrm{HCl}$, which produces $\mathrm{Cl}_{2}$. Photolysis of $\mathrm{Cl}_{2}$ then produces $\mathrm{ClO}_{\mathrm{x}}\left(=\mathrm{Cl}+\mathrm{ClO}+2 \times \mathrm{Cl}_{2} \mathrm{O}_{2}\right)$. A similar cycle is also possible through the formation of $\mathrm{ClONO}_{2}$ instead of $\mathrm{HOCl}$, which is, however, not more than about $0.1 \%$ as fast at this time in the simulation for ozone mixing rations below $0.5 \mathrm{ppmv}$. The chlorine deactivation into $\mathrm{HCl}$ occurs through the reactions $\mathrm{Cl}+\mathrm{CH}_{4}$ and $\mathrm{Cl}+\mathrm{CH}_{2} \mathrm{O}$. $\mathrm{HOCl}$ is being formed mainly by the reaction $\mathrm{ClO}+\mathrm{HO}_{2}$ (rather than by heterogeneous reaction of $\mathrm{ClONO}_{2}$ with $\mathrm{H}_{2} \mathrm{O}$ ) in this simulation, and it is decomposed by photolysis as well as through heterogeneous reactions. This chain stops if all chlorine compounds are deactivated into $\mathrm{HCl}$. The fast chlorine 
deactivation into the reservoir $\mathrm{HCl}$ can be elucidated by looking at the net chlorine activation and deactivation rates that are shown in panel $\mathrm{f}$ of Fig. 2. The blue line corresponds to the sum of all activation reactions that decompose $\mathrm{HCl}$ (or $\mathrm{ClONO}_{2}$ ), mainly the heterogeneous reaction of $\mathrm{HOCl}+\mathrm{HCl}$. The red line corresponds to the sum of all deactivation reactions in which $\mathrm{HCl}$ or $\mathrm{ClONO}_{2}$ are formed, mainly $\mathrm{Cl}+\mathrm{CH}_{4}$, $\mathrm{Cl}+\mathrm{CH}_{2} \mathrm{O}$. It is apparent that the chlorine activation and deactivation rates are approximately balanced and they increase to values of the order of $10 \mathrm{ppbv}$ per day in the period before the ozone minimum. This deactivation rate would lead to a complete chlorine deactivation within about $6 \mathrm{~h}$ if heterogeneous chlorine activation did not occur at the same time. The chlorine activation rate in late October and November is mainly due to the gas phase reaction of $\mathrm{HCl}+\mathrm{OH}$ and $\mathrm{ClONO}_{2}$ photolysis.

For a better focus on the short time period before the minimum ozone occurs, Fig. 4 shows the model results for this two-week period again, but as a function of ozone mixing ratio on a logarithmic scale. The time is indicated by the grey shadings that correspond to every other day, while lower ozone mixing ratios correspond to the later times of the period. Panel a of this figure shows the temperature and panel b shows how the development of chlorine species depends on ozone for the chosen example. The simulated $\mathrm{HCl}$ begins to increase rapidly as ozone mixing ratios fall below 0.1 ppmv. When the ozone minimum is reached, no chlorine compounds other than $\mathrm{HCl}$ are present in significant amounts. Panel c of Fig. 4 shows the simulated rates for chlorine activation and deactivation from and into the reservoir species $\left(\mathrm{HCl}, \mathrm{ClONO}_{2}\right)$, respectively. As long as it is cold enough for the presence of PSCs and as long as $\mathrm{HOCl}$ is formed by the reaction $\mathrm{ClO}+\mathrm{HO}_{2}$, the formation of $\mathrm{HOCl}$ is immediately followed by heterogeneous chlorine activation through the reaction $\mathrm{HCl}+\mathrm{HOCl}$. In the case of temperatures near or above $195 \mathrm{~K}$ (e.g. in Fig. 4 at 0.7 ppmv of ozone), the chlorine activation rate sinks below the deactivation rate. $\mathrm{HCl}$ mixing ratios start to increase if the ozone mixing ratio is low enough for the formation of $\mathrm{HCl}$ to exceed chlorine activation despite the low temperatures; in this representative simulation this occurs below ozone mixing ratios of about $0.05 \mathrm{ppmv}$. The role of ozone in controlling the re-formation of chlorine reservoirs $\mathrm{HCl}$ (and $\mathrm{ClONO}_{2}$ ) in polar spring was first noted by Douglass et al. (1995). For low ozone mixing ratios, the formation of $\mathrm{HCl}$ is strongly dominant. The main reason for the increase in chlorine deactivation rate with decreasing ozone mixing ratio is the strongly increasing $\mathrm{Cl} / \mathrm{ClO}$ ratio (Douglass et al., 1995; Grooß et al., 1997) that is plotted in panel d. This increase is caused by slowing down the rate of the reaction $\mathrm{Cl}+\mathrm{O}_{3} . \mathrm{Cl}$ is formed from $\mathrm{ClO}$ through the multiple reactions depicted in Fig. 3 , including $\mathrm{ClO}+\mathrm{ClO} \rightarrow \mathrm{Cl}_{2} \mathrm{O}_{2}$, followed by $\mathrm{Cl}_{2} \mathrm{O}_{2}$ photolysis and the reaction $\mathrm{ClO}+\mathrm{CH}_{3} \mathrm{O}_{2}$ of the $\mathrm{CH}_{4}$ oxidation chain. Due to this dependence, the net chlorine deactivation rate into $\mathrm{HCl}$ increases with decreasing ozone mixing ratio. However, the formation rate of $\mathrm{HOCl}$ by the reaction $\mathrm{ClO}+\mathrm{HO}_{2}$ also increases with decreasing ozone mixing ratio due to the enhanced $\mathrm{HO}_{2}$ formation, which is caused as a result of the increase of both the reaction rates of $\mathrm{Cl}+\mathrm{CH}_{2} \mathrm{O}$ and $\mathrm{ClO}+\mathrm{CH}_{3} \mathrm{O}_{2}$. This enhanced $\mathrm{HO}_{2}$ formation causes an enhanced $\mathrm{HOCl}$ formation rate and thus makes the enhanced chlorine activation rate by the heterogeneous reaction $\mathrm{HOCl}+\mathrm{HCl}$ possible. During that period, a close balance between chlorine activation and deactivation prevails. The $\mathrm{HO}_{2}$ production via the reaction $\mathrm{ClO}+\mathrm{CH}_{3} \mathrm{O}_{2}$ (Crutzen et al., 1992) is particularly important here. In a sensitivity simulation with this reaction left out the minimum ozone mixing ratios were typically larger by a factor of 5-10 and remained always greater than about $30 \mathrm{ppbv}$ (not shown). The net chlorine deactivation rate increases with decreasing ozone mixing ratio until the point when all active chlorine is irreversibly deactivated into $\mathrm{HCl}$. The irreversible, very rapid deactivation occurs, when gas-phase production of $\mathrm{HCl}$ significantly exceeds the concurrent $\mathrm{HOCl}$ production. The specific ozone mixing ratio at which this complete chlorine deactivation takes place depends critically on the composition and temperature history of the air parcel, as will be shown below. From Fig. 4, it can also be seen that during darkness no major changes to the chemical composition occur. In darkness, the active chlorine $\mathrm{ClO}_{\mathrm{x}}$ is predominantly in the form of the night reservoir $\mathrm{Cl}_{2} \mathrm{O}_{2}$, so that no ozone depletion or significant change in chlorine activation occurs.

We also investigated the catalytic cycles responsible for the ozone depletion and their behaviour in this 14-day period. The rate-limiting steps of the most important catalytic destruction cycles are plotted in panels $2 \mathrm{~g}$ and $4 \mathrm{e}$. The most effective catalytic ozone loss cycles are the $\mathrm{ClO}$-dimer cycle (Molina and Molina, 1987) and the ClO-BrO cycle (McElroy et al., 1986) plotted in orange and green, respectively. The ozone depletion cycle involving $\mathrm{HOCl}$ photolysis originally had proposed by Solomon et al. (1986) is also shown. Although this cycle is slower than the $\mathrm{ClO}+\mathrm{BrO}$ cycle under high ozone concentrations, it gains importance with decreasing ozone and becomes faster than $\mathrm{ClO}+\mathrm{BrO}$ as ozone mixing ratios fall below about $0.1 \mathrm{ppmv}$. Other catalytic ozone loss cycles as the $\mathrm{BrO}-\mathrm{BrO}$ cycle are much less effective. After the ozone minimum is reached, the sum of the ozone loss rates drops below ozone production (black dotted lines) due to oxygen photolysis (black solid line) and other ozone production chains discussed below.

\subsection{Sensitivity studies}

In this section, we investigate the sensitivity of the simulated ozone mixing ratio with respect to several model assumptions. For that purpose, we first performed additional box-model simulations identical to the one described above but with slightly different initial ozone mixing ratios. Figure 5 shows four additional simulations in which the initial ozone mixing ratio was changed between 2.2 and 2.6 ppmv. 


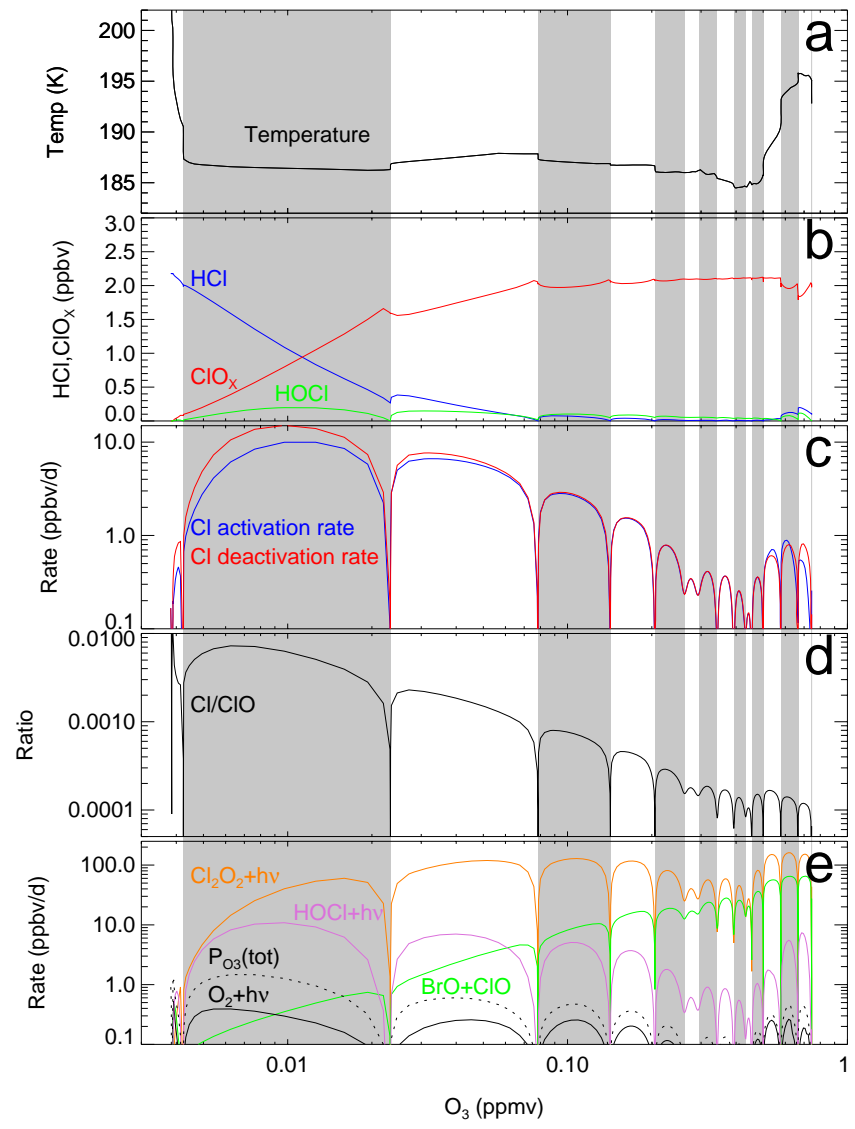

Fig. 4. Parameters before the ozone minimum for the time 17 September-1 October 2003 (grey shaded area in Fig. 2) plotted as a function of $\mathrm{O}_{3}$ mixing ratio. (a) temperature, (b) chlorine compounds, (c) net rates of chlorine activation and deactivation, (d) $\mathrm{Cl} / \mathrm{ClO}$ ratio, (e) rates of catalytic cycles involving ozone. Here, the reaction rates are not plotted as running averages. The grey shadings correspond to every other day defined by the local maxima of the solar zenith angle. Different days of the chosen periods are also visible, as during the night the reaction rates and the $\mathrm{Cl}$ concentration typically decrease by many orders of magnitude.

Surprisingly, each of the five simulations shows both very different minimum ozone mixing ratios and different times at which these minima are reached. Moreover, there is no obvious relationship between the initial ozone mixing ratio and either the time or the minimum ozone mixing ratio. A similar comparison for a trajectory through a different ozone sonde observation also reveals this behaviour (not shown). The reason for this behaviour of the model results was investigated by considering the differences from the reference simulation. Similar to the reference simulation, in the sensitivity runs the ozone depletion was terminated by an irreversible chlorine deactivation into $\mathrm{HCl}$, after which no chlorine activation occurred despite PSC surfaces being available. Chlorine deactivation can occur when temperatures temporarily rise above around $195 \mathrm{~K}$, i.e. above the threshold temperature for chlo-

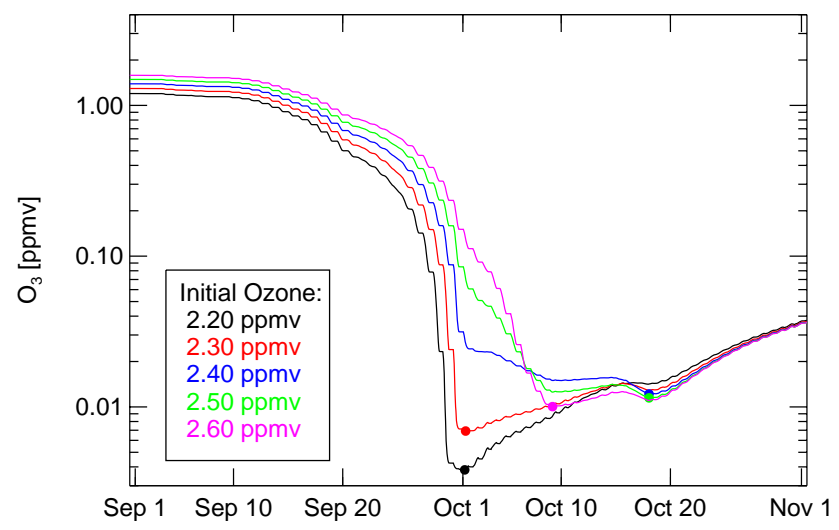

Fig. 5. Sensitivity to ozone initialisation; four additional box-model simulations identical to the reference simulation, but with different initial ozone mixing ratios (see legend). The time of the minimum ozone mixing ratio is marked by a solid coloured circle.

rine activation. As explained above, the formation of $\mathrm{HCl}$ is also increasingly favoured with decreasing ozone mixing ratio. Even though the individual air parcel trajectories are identical in all of the simulations shown in Fig. 5, the low ozone mixing ratios below about $0.1 \mathrm{ppmv}$ are reached at different times and thus at different temperatures. It is therefore possible that in two almost identical simulations with only a slightly different ozone initialisation, one simulation shows complete irreversible chlorine deactivation into $\mathrm{HCl}$ at a relatively large ozone mixing ratio, while in other simulations some active chlorine could remain thus permitting $\mathrm{ClONO}_{2}$ formation, later chlorine activation and further ozone depletion. The lowest ozone mixing ratios were reached when the temperature at the ozone minimum stayed below $190 \mathrm{~K}$ until the final days before the ozone minimum. Notably, the processes discussed above that lead to complete deactivation into $\mathrm{HCl}$ also dominate under these conditions. The sensitive dependence of the timing of deactivation on temperature and low ozone mixing ratios makes it nearly impossible to simulate the exact ozone minimum for a single air parcel. It also provides a possible explanation for the variability of ozone observations reported by Solomon et al. (2005).

The simulated development of ozone mixing ratios also depends on the initial chlorine activation. This was investigated by repeating the reference simulation but initialised with a larger initial chlorine activation in which about $75 \%$ instead of $50 \%$ of $\mathrm{Cl}_{\mathrm{y}}$ was initialised as $\mathrm{ClO}_{\mathrm{x}}$. The result of the increased chlorine activation is, of course, faster ozone depletion at the beginning of the spring season. However, also here the general behaviour of the temporal development of simulated ozone dependence on the initial ozone mixing ratio remained unchanged (not shown).

The vertical re-distribution of $\mathrm{NO}_{\mathrm{y}}$ due to sedimenting $\mathrm{HNO}_{3}$-containing particles is only considered in the 3dimensional CLaMS simulation. However, in the box-model 
simulation it is possible to include denitrification by removing $\mathrm{HNO}_{3}$ from the model when NAT is present by a simple parametrisation (Grooß et al., 2002). This parametrisation was used here to study the sensitivity of the results with respect to denitrification. The denitrification was adjusted such that about 3 ppbv of $\mathrm{HNO}_{3}$ remained in the box in November, consistent with ACE-FTS observations (Jones et al., 2011b). Individual simulations look different when the denitrification is included and all other model parameters remain identical. However, in general in the case of increased denitrification, the minimum ozone mixing ratio is somewhat larger and it is reached at a later time. This can be explained by two effects. First, a slightly lower chlorine activation, which is due to less $\mathrm{NO}_{2}$ being available, which makes the formation of $\mathrm{ClONO}_{2}$ slower and thus decreases the heterogeneous activation through $\mathrm{ClONO}_{2}+\mathrm{HCl}$. Second, less $\mathrm{HNO}_{3}$ causes smaller surfaces of solid and liquid PSCs, which slows down the heterogeneous chlorine activation reactions. With the denitrification parametrisation, the maximum of the chlorine deactivation rate is about $50 \%$ lower than for the reference simulation. However, also here the general behaviour of the temporal development of simulated ozone dependence on the initial ozone mixing ratio remained unchanged (not shown). Denitrification also causes a slower rate of increase in ozone after the minimum, as will be discussed below.

\subsection{Ozone recovery}

From the ozone sonde measurements at the South Pole (Fig. 1), it is evident that after early October the lower envelope of the ozone observations increases again with time. Possible explanations for this increase are either in situ production of ozone or mixing with air masses containing larger ozone mixing ratios. However, the increase occurs smoothly, suggesting a likely role for chemistry rather than mixing alone, which would be expected to be episodic and variable. In the box-model results, the in situ chemical ozone production can be probed. To investigate the latitude and altitude dependence of the in situ ozone production, multiple boxmodel simulations were performed along artificial trajectories in which latitude, temperature and pressure level were kept constant over the period from October to December.

These simulations were initialised assuming complete chlorine deactivation $\left(\mathrm{HCl}=\mathrm{Cl}_{\mathrm{y}}\right), 1 \mathrm{ppbv}$ ozone, and $4.5 \mathrm{ppbv} \mathrm{NO}_{\mathrm{y}}$ corresponding to moderate denitrification. The analysis of these simulations shows that three reaction chains are responsible for the ozone production. One of these is the well-known production by oxygen photolysis (Chapman, 1930).

$$
\begin{aligned}
\mathbf{O}_{2}+\mathbf{h} \boldsymbol{v} & \rightarrow \mathbf{2 O} \\
\mathrm{O}+\mathrm{O}_{2}+\mathrm{M} & \rightarrow \mathrm{O}_{3} \\
\hline 3 \mathrm{O}_{2} & \rightarrow 2 \mathrm{O}_{3}
\end{aligned}
$$

Two other reaction chains make important contributions to the modelled ozone production, namely the oxidation of $\mathrm{CO}$ and $\mathrm{CH}_{4}$.

$$
\begin{aligned}
\mathbf{C O}+\mathbf{O H} & \rightarrow \mathbf{H}+\mathbf{C O}_{2} \\
\mathrm{H}+\mathrm{O}_{2}+\mathrm{M} & \rightarrow \mathrm{HO}_{2} \\
\mathrm{HO}_{2}+\mathrm{NO} & \rightarrow \mathrm{NO}_{2}+\mathrm{OH} \\
\mathrm{NO}_{2}+h v & \rightarrow \mathrm{NO}+\mathrm{O} \\
\mathrm{O}+\mathrm{O}_{2}+\mathrm{M} & \rightarrow \mathrm{O}_{3} \\
\mathrm{CO}+2 \mathrm{O}_{2} & \rightarrow \mathrm{CO}_{2}+\mathrm{O}_{3}
\end{aligned}
$$

and

$$
\begin{aligned}
\mathbf{C H}_{4}+\mathbf{C l} & \rightarrow \mathbf{C H}_{3}+\mathbf{H C l} \\
\mathrm{HCl}+\mathrm{OH} & \rightarrow \mathrm{Cl}+\mathrm{H}_{2} \mathrm{O} \\
\mathrm{CH}_{3}+\mathrm{O}_{2}+\mathrm{M} & \rightarrow \mathrm{CH}_{3} \mathrm{OO} \\
\mathrm{CH}_{3} \mathrm{OO}+\mathrm{NO} & \rightarrow \mathrm{NO}_{2}+\mathrm{CH}_{2} \mathrm{O}+\mathrm{H} \\
\mathrm{H}+\mathrm{O}_{2}+\mathrm{M} & \rightarrow \mathrm{HO}_{2} \\
\mathrm{HO}_{2}+\mathrm{NO} & \rightarrow \mathrm{NO}_{2}+\mathrm{OH} \\
\mathrm{NO}_{2}+h v & \rightarrow \mathrm{NO}+\mathrm{O} \quad(2 \times) \\
\mathrm{O}+\mathrm{O}_{2}+\mathrm{M} & \rightarrow \mathrm{O}_{3} \quad(2 \times)
\end{aligned}
$$$$
\mathrm{CH}_{4}+4 \mathrm{O}_{2} \rightarrow \mathrm{CH}_{2} \mathrm{O}+\mathrm{H}_{2} \mathrm{O}+2 \mathrm{O}_{3}
$$

Alternatively, when replaced by the following reaction, the first 2 reactions of Reaction Chain R3 result in a chain with the same sum reaction.

$$
\mathrm{CH}_{4}+\mathrm{OH} \rightarrow \mathrm{CH}_{3}+\mathrm{H}_{2} \mathrm{O}
$$

A further minor ozone production chain is also initiated by the oxidation of $\mathrm{CH}_{2} \mathrm{O}$, which is not considered in detail here. In each of the above reaction chains, the slowest reaction that determines the ozone production rate is written in bold face. (Note that in the presence of PSCs and active chlorine the heterogeneous reaction $\mathrm{HOCl}+\mathrm{HCl}$ occurs in parallel to $\mathrm{HCl}+\mathrm{OH}$ in Reaction Chain R3. In that case, the reaction $\mathrm{CH}_{3} \mathrm{OO}+\mathrm{NO}$ determines the rate of Reactions Chains R3 and R4). For typical stratospheric ozone mixing ratios, the ozone production rates of Reaction Chains $\mathrm{R} 2$ to $\mathrm{R} 4$ are of the order of $1 \mathrm{ppbv}$ per day and therefore relatively unimportant. These cycles dominate ozone production here due to the low solar elevation. Figure 6 shows the simulated ozone increase between 1 October and 30 November for the three pressure levels 100,70 , and $50 \mathrm{hPa}$. The dashed line corresponds to the ozone increase due to oxygen photolysis only (Reaction Chain R1). The dotted lines correspond to the sum of the rates limiting Reactions Chains R1 to R4 including oxygen photolysis. It is slightly larger than the calculated net ozone production (solid lines), because some ozone depletion cycles also occur (see also Fig. $2 \mathrm{~g}$ ). 


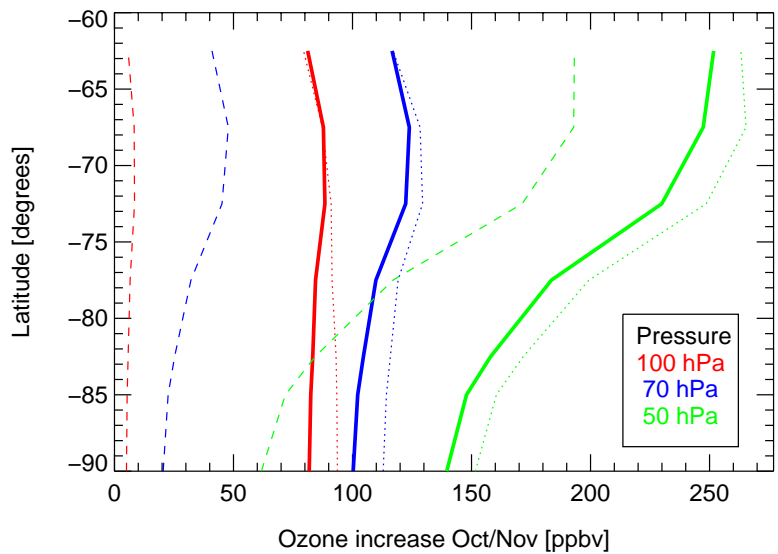

Fig. 6. Simulated ozone increase between 1 October and 30 November as a function of latitude for three pressure levels using overhead ozone profile from climatology. Solid lines indicate the simulated ozone increase, dashed lines show the ozone increase due to oxygen photolysis (Reaction Chain R1). Dotted lines show the sum of ozone production by reaction chains 1 to 4 .

In Figs. $2 \mathrm{~g}$ and $4 \mathrm{e}$, the dotted black lines correspond to the ozone production rate due to the sum of all ozone production chains (Reaction Chains R1 to R4). This part of the ozone production increases with increasing altitude. It also increases with distance from the South Pole due to the increasing solar elevation. The fraction of ozone production caused by the $\mathrm{CO}$ and $\mathrm{CH}_{4}$ oxidation (Reaction Chains $\mathrm{R} 2$ to R4) corresponds to the difference between the dotted and the dashed line. It remains approximately constant with altitude and latitude.

For the results shown in Fig. 6, the oxygen photolysis rate was calculated using a climatological overhead ozone profile (Grooß and Russell, 2005) that contains average ozone mixing ratios for the ozone hole time period. However, it is possible that the ozone profile above the observations showing very low ozone mixing ratio at the lower envelope may also be significantly below average. This would cause an increase in the oxygen photolysis rate and therefore in the ozone production rate. To investigate this sensitivity, we repeated the simulations assuming a reduced overhead ozone profile. The ozone profile was reduced by a factor of 5 between 30 and $150 \mathrm{hPa}$ south of $65^{\circ} \mathrm{S}$. The results obtained with this reduced overhead ozone profile are displayed in Fig. 7. A larger ozone production is evident, especially at the $50 \mathrm{hPa}$ level towards the vortex edge. However, air masses with ozone mixing ratios well below average may not remain vertically aligned over a period of two months.

The ozone production rate due to Reaction Chains (R2) and (R3) depends on the available active nitrogen $\left(\mathrm{NO}_{\mathrm{x}}=\mathrm{NO}+\mathrm{NO}_{2}\right)$ and is strongly influenced by denitrification. A decrease in $\mathrm{NO}_{\mathrm{y}}$ also implies a decrease in $\mathrm{NO}_{\mathrm{x}}$. The $\mathrm{NO}_{\mathrm{x}}$ dependence of ozone production rates was already investigated in the context of evaluating the impact of aircraft

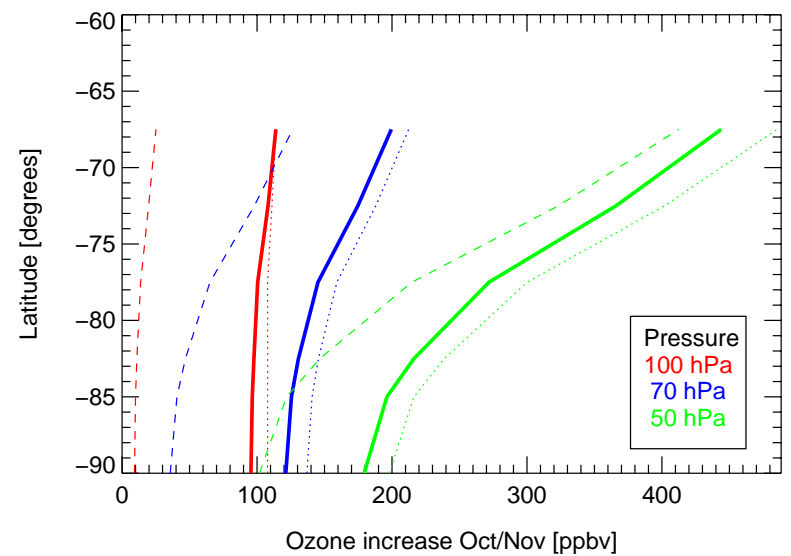

Fig. 7. As Fig. 6, but using an overhead ozone profile reduced by a factor of 5 between 30 and $150 \mathrm{hPa}$.

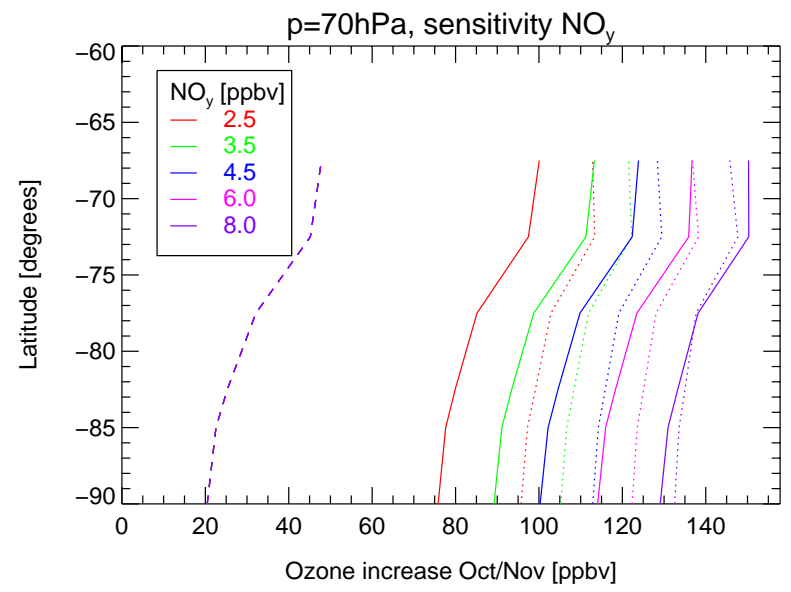

Fig. 8. Simulated ozone increase between 1 October and 30 November for the $70 \mathrm{hPa}$ level (blue line in Fig. 6) for different values of $\mathrm{NO}_{\mathrm{y}}$. The ozone increase due to oxygen photolysis (dashed line) is the same for all simulations.

emissions on the chemical composition of the tropopause region (e.g., Grooß et al., 1998). Figure 8 shows the sensitivity of ozone production with respect to $\mathrm{NO}_{\mathrm{y}}$ (ranging between 2.5 and $8 \mathrm{ppbv}$ ) for the simulation on the $70 \mathrm{hPa}$ level. Figure 8 shows that the ozone increase is slower for more denitrified air. This demonstrates the importance of ozone production due to $\mathrm{CO}$ and $\mathrm{CH}_{4}$ oxidation. An increase in $\mathrm{NO}_{\mathrm{x}}$ increases the $\mathrm{Cl} / \mathrm{ClO}$ ratio due to the faster $\mathrm{NO}+\mathrm{ClO}$ reaction and a larger $\mathrm{OH} / \mathrm{HO}_{2}$ ratio due to the faster $\mathrm{NO}+\mathrm{HO}_{2}$ reaction.

For comparison with the range of observed ozone observations, we now show sensitivity simulations for realistic trajectories that include diabatic descent and latitude variations. The box-model simulations of the same kind as shown in Sect. 3.1 were initialised on 1 August interpolated from the 3-dimensional CLaMS CTM simulation. 

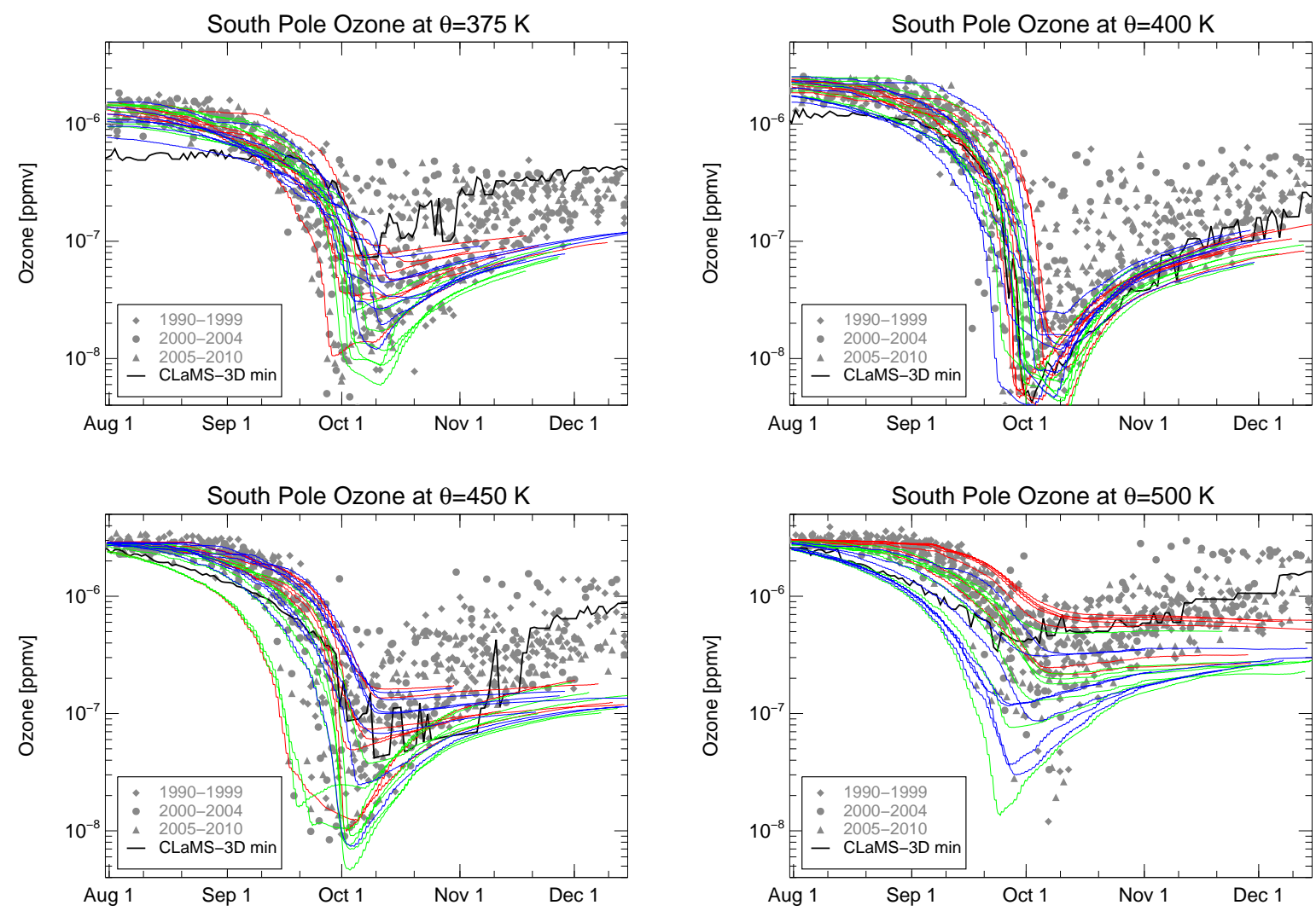

Fig. 9. Comparison of South Pole ozone observations with box-model simulations for 4 different levels. The vertical coordinate is potential temperature. South Pole observations for different yeas are plotted as grey symbols. CLaMS box-model simulations are shown for 21 trajectories per level that pass the South Pole on this level at different times in 2003 (red: 20-26 September; green: 27 September-3 October; blue: 4-10 October). For trajectories that reach latitudes north of $50^{\circ} \mathrm{S}$, only the results up to this latitude are shown. The black line corresponds to the minimum ozone mixing ratio of the CLaMS 3-D simulation poleward of $75^{\circ} \mathrm{S}$ equivalent latitude for the individual levels.

To obtain realistic initial chlorine activation, the initialisation of $\mathrm{ClONO}_{2}$ and $\mathrm{HCl}$ was taken from a climatology based on ACE-FTS observations (Jones et al., 2011a). To avoid unrealistic denitrification, the lowest $\mathrm{NO}_{\mathrm{y}}$ and $\mathrm{H}_{2} \mathrm{O}$ mixing ratios derived from the CLaMS 3-D simulation were not allowed to sink below $2.0 \mathrm{ppbv}$ and $2.0 \mathrm{ppmv}$, respectively. It is important to note that part of the ozone increase in November and December on the $70 \mathrm{hPa}$ level (Fig. 1) is neither due to photochemical ozone production nor mixing. It is caused by the typical climatological temperature increase in spring, which leads to an increase of potential temperature on a constant pressure level. The change in potential temperature at $70 \mathrm{hPa}$ between 1 October and 1 December is about $38 \mathrm{~K}$. Since in spring the air masses remain on slowly descending potential temperature levels, the time series of observations on constant pressure levels in Fig. 1 corresponds to different altitude origins. Therefore we compare the simulations with data on potential temperature levels. Here, the box-model simulations were performed along trajectories that pass exactly over the South Pole on 21 days (20 September to 10 October 2003) for each of the potential temperature levels
$375 \mathrm{~K}, 400 \mathrm{~K}, 450 \mathrm{~K}$, and $500 \mathrm{~K}$. For the period between 1 October and 1 December, the average diabatic descent for the chosen trajectory for the lower three levels $(375 \mathrm{~K}, 400 \mathrm{~K}$, $450 \mathrm{~K}$ ) is below $10 \mathrm{~K}$ and $20 \mathrm{~K}$ for the $500 \mathrm{~K}$ level.

Although the latitude of trajectories changes with time, we argue that the simulated chemical ozone production should be similar to the South Pole observations, because, to first order, similar ozone loss would be expected for an air parcel starting at the pole and ending at latitude $x$ compared with an air parcel starting at latitude $x$ and ending at the pole for the same time period. This is because the noontime solar elevation increases from pole to mid-latitude, while the time of solar hours per day increases from mid-latitude to the pole. Further, the results of single box-model runs can only be taken as an example, since the development of the results very sensitively depends on the initial ozone mixing ratio as shown in the previous sections. The simulated ozone mixing ratios for these simulations are shown in Fig. 9. Generally it can be seen that the simulations overlay the range of the observations. At the $375 \mathrm{~K}$ and $400 \mathrm{~K}$ levels, the simulated ozone for many of the trajectories follows the lower 
envelope of the ozone observations well. On the $500 \mathrm{~K}$ potential temperature level, the majority of the box-model simulations have ozone mixing ratios below the lower envelope of the observations. An important reason for the difference at the $500 \mathrm{~K}$ level is diabatic descent. For example, the lower envelope of the South Pole observations on 1 December at $480 \mathrm{~K}$ is around $340 \mathrm{ppbv}$ while at $500 \mathrm{~K}$ it is $480 \mathrm{ppbv}$, implying that a $20 \mathrm{~K}$ descent deplacement would be important to the results. Generally, mixing of air masses which is not considered in the box-model simulations would also yield an increase in ozone.

The minimum ozone mixing ratio between equivalent latitudes of $75^{\circ} \mathrm{S}$ and $90^{\circ} \mathrm{S}$ of the CLaMS 3-D simulation is plotted as a thick black line. In August at the lower levels of $375 \mathrm{~K}$ and $400 \mathrm{~K}$ about $5 \%$ and $1 \%$ of the CLaMS air parcels are below the envelope of the ozone sonde observations, respectively. This is most likely due to deficits in the ozone initialisation at the lower altitudes, which are, however, not important for the conclusions drawn here. The CLaMS 3-D simulation also fails to reach the minimum ozone mixing ratios that are seen in the observations, probably due to the low resolution of the model simulation. On the $400 \mathrm{~K}$ and $450 \mathrm{~K}$ level, the increase in minimum ozone in October and November in the 3-D simulation is faster than in the box-model simulations. This additional increase can be explained by mixing, which is potentially overestimated in the 3-D CLaMS simulation. However, from the results shown it is clear that in situ ozone production by the reaction chains mentioned above can explain much of the observed ozone increase in October and November.

\section{Conclusions}

In this paper, we have discussed several processes that are responsible for Antarctic ozone depletion. We showed that the observed very low ozone mixing ratios in late September and early October can be reproduced in box-model simulations. A critical constraint on the minimum ozone that can be reached is fast irreversible chlorine deactivation into $\mathrm{HCl}$, which is triggered by very low ozone mixing ratios and makes the ozone loss self-limiting. Ozone depletion can therefore cease as ozone falls to very low values, even though surfaces of solid and/or liquid PSCs are still present. The timing and the value of this minimum ozone mixing ratio are very sensitive to different model parameters, in particular the initial ozone mixing ratio, therefore it is not possible in all cases to exactly predict these parameters for a single air mass. The increase of the ozone mixing ratios after the minimum is mostly explained by in situ chemical ozone production both by oxygen photolysis and as a consequence of methane and carbon monoxide oxidation. An additional ozone increase caused by mixing ond/or descent is also possible, particularly for later times in the spring season.
Acknowledgements. We thank Herman Smit and Peter von der Gathen for helpful discussions on the detection limits of ozone sondes. This work was supported by the RECONCILE project of the European Commission Seventh Framework Programme (FP7) under the Grant number RECONCILE-226365-FP7-ENV-2008-1.

Edited by: D. Knopf

\section{References}

Becker, G., Grooß, J.-U., McKenna, D. S., and Müller, R.: Stratospheric photolysis frequencies: Impact of an improved numerical solution of the radiative transfer equation, J. Atmos. Chem., 37, 217-229, doi:10.1023/A:1006468926530, 2000.

Brown, P. N., Byrne, G. D., and Hindmarsh, A. C.: VODE: A variable coefficient ODE solver, SIAM J. Sci. Stat. Comput., 10, 1038-1051, 1989.

Carslaw, K. S. and Peter, T.: Uncertainties in reactive uptake coefficients for solid stratospheric particles -1 . Surface chemistry, Geophys. Res. Lett., 24, 1743-1746, 1997.

Carver, G. D. and Scott, P. A.: IMPACT: an implicit time integration scheme for chemical species and families, Ann. Geophys., 18, 337-346, 2000, http://www.ann-geophys.net/18/337/2000/.

Carver, G. D., Brown, P. D., and Wild, O.: The ASAD atmospheric chemistry integration package and chemical reaction database, Comput. Phys. Comm., 105, 197-215, 1997.

Chapman, S.: A theory of upper atmospheric ozone, Mem. Roy. Soc., 3, 103-109, 1930.

Crutzen, P. J., Müller, R., Brühl, C., and Peter, T.: On the potential importance of the gas phase reaction $\mathrm{CH}_{3} \mathrm{O}_{2}+\mathrm{ClO} \rightarrow$ $\mathrm{ClOO}+\mathrm{CH}_{3} \mathrm{O}$ and the heterogeneous reaction $\mathrm{HOCl}+\mathrm{HCl} \rightarrow$ $\mathrm{H}_{2} \mathrm{O}+\mathrm{Cl}_{2}$ in "ozone hole" chemistry, Geophys. Res. Lett., 19, 1113-1116, doi:10.1029/92GL01172, 1992.

Douglass, A. R., Schoeberl, M. R., Stolarski, R. S., Waters, J. W., Russell III, J. M., Roche, A. E., and Massie, S. T.: Interhemispheric differences in springtime production of $\mathrm{HCl}$ and $\mathrm{ClONO}_{2}$ in the polar vortices, J. Geophys. Res., 100, 13967-13978, 1995.

Farman, J. C., Gardiner, B. G., and Shanklin, J. D.: Large losses of total ozone in Antarctica reveal seasonal $\mathrm{ClO}_{\mathrm{X}} / \mathrm{NO}_{\mathrm{X}}$ interaction, Nature, 315, 207-210, 1985.

Grooß, J.-U.: Modelling of Stratospheric Chemistry based on HALOE/UARS Satellite Data, PhD thesis, University of Mainz, Germany, 1996.

Grooß, J.-U. and Russell, J. M.: Technical note: A stratospheric climatology for $\mathrm{O}_{3}, \mathrm{H}_{2} \mathrm{O}, \mathrm{CH}_{4}, \mathrm{NO}_{\mathrm{x}}, \mathrm{HCl}$, and $\mathrm{HF}$ derived from HALOE measurements, Atmos. Chem. Phys., 5, 2797-2807, doi:10.5194/acp-5-2797-2005, 2005.

Grooß, J.-U., Pierce, R. B., Crutzen, P. J., Grose, W. L., and Russell III, J. M.: Re-formation of chlorine reservoirs in southern hemisphere polar spring, J. Geophys. Res., 102, 13141-13152, doi:10.1029/96JD03505, 1997.

Grooß, J.-U., Brühl, C., and Peter, T.: Impact of aircraft emissions on tropospheric and stratospheric ozone, I: Chemistry and 2-D model results, Atmos. Environ., 32, 3173-3184, 1998.

Grooß, J.-U., Günther, G., Konopka, P., Müller, R., McKenna, D. S., Stroh, F., Vogel, B., Engel, A., Müller, M., Hoppel, K., Bevilacqua, R., Richard, E., Webster, C. R., Elkins, J. W., Hurst, D. F., Romashkin, P. A., and Baumgardner, D. G.: Simula- 
tion of ozone depletion in spring 2000 with the Chemical Lagrangian Model of the Stratosphere (CLaMS), J. Geophys. Res., 107, 8295, doi:10.1029/2001JD000456, 2002.

Grooß, J.-U., Konopka, P., and Müller, R.: Ozone chemistry during the 2002 Antarctic vortex split, J. Atmos. Sci., 62, 860-870, 2005a.

Grooß, J.-U., Günther, G., Müller, R., Konopka, P., Bausch, S., Schlager, H., Voigt, C., Volk, C. M., and Toon, G. C.: Simulation of denitrification and ozone loss for the Arctic winter 2002/2003, Atmos. Chem. Phys., 5, 1437-1448, doi:10.5194/acp-5-14372005, 2005b.

Hanson, D. R.: Reaction of $\mathrm{ClONO}_{2}$ with $\mathrm{H}_{2} \mathrm{O}$ and $\mathrm{HCl}$ in sulfuric acid and $\mathrm{HNO}_{3} / \mathrm{H}_{2} \mathrm{SO}_{4} / \mathrm{H}_{2} \mathrm{O}$ mixtures, J. Phys. Chem. A, 102, 4794-4807, 1998.

Hanson, D. R. and Ravishankara, A. R.: Reaction of $\mathrm{ClONO}_{2}$ with $\mathrm{HCl}$ on NAT, NAD, and frozen sulfuric acid and hydrolysis of $\mathrm{N}_{2} \mathrm{O}_{5}$ and $\mathrm{ClONO}_{2}$ on frozen sulfuric acid, J. Geophys. Res., 98, 22931-22936, 1993.

Jones, A., Qin, G., Strong, K., Walker, K. A., McLinden, C., M. Toohey, T., Kerzenmacher, Bernath, P., and Boone, C.: A global inventory of stratospheric NOy from ACE-FTS, J. Geophys. Res., 116, D17304, doi:10.1029/2010JD015465, 2011a.

Jones, A., Walker, K. A., Jin, J. J., Taylor, J. R., Boone, C. D., Bernath, P. F., Brohede, S., Manney, G. L., McLeod, S., Hughes, R., and Daffer, W. H.: Technical Note: A trace gas climatology derived from the Atmospheric Chemistry Experiment Fourier Transform Spectrometer dataset, Atmos. Chem. Phys. Discuss., 11, 29845-29882, doi:10.5194/acpd-11-29845-2011, , 2011 b.

Konopka, P., Steinhorst, H.-M., Grooß, J.-U., Günther, G., Müller, R., Elkins, J. W., Jost, H.-J., Richard, E., Schmidt, U., Toon, G., and McKenna, D. S.: Mixing and Ozone Loss in the 1999-2000 Arctic Vortex: Simulations with the 3-dimensional Chemical Lagrangian Model of the Stratosphere (CLaMS), J. Geophys. Res., 109, D02315, doi:10.1029/2003JD003792, 2004.

Lien, C.-Y., Lin, W.-Y., Chen, H.-Y., Huang, W.-T., Jin, B., Chen, I.-C., and Lin, J. J.: Photodissociation cross sections of $\mathrm{ClOOCl}$ at 248.4 and $266 \mathrm{~nm}, \mathrm{~J}$. Chem. Phys., 131, 174301, doi:10.1063/1.3257682, 2009.

McElroy, M. B., Salawitch, R. J., Wofsy, S. C., and Logan, J. A.: Antarctic ozone: Reductions due to synergistic interactions of chlorine and bromine, Nature, 321, 759-762, 1986.

McKenna, D. S., Konopka, P., Grooß, J.-U., Günther, G., Müller, R., Spang, R., Offermann, D., and Orsolini, Y.: A new Chemical Lagrangian Model of the Stratosphere (CLaMS): 1. Formulation of advection and mixing, J. Geophys. Res., 107, 4309, doi:10.1029/2000JD000114, 2002a.
McKenna, D. S., Grooß, J.-U., Günther, G., Konopka, P., Müller, R., Carver, G., and Sasano, Y.: A new Chemical Lagrangian Model of the Stratosphere (CLaMS): 2. Formulation of chemistry scheme and initialization, J. Geophys. Res., 107, 4256, doi:10.1029/2000JD000113, 2002b.

Meier, R. R., Anderson, D. E., J., and Nicolet, M.: Radiation Field in the Troposphere and Stratosphere from 240-1000 nm - I: General Analysis, Planet Space Sci., 30, 923-933, 1982.

Molina, L. T. and Molina, M. J.: Production of $\mathrm{Cl}_{2} \mathrm{O}_{2}$ from the self-reaction of the ClO radical, J. Phys. Chem., 91, 433-436, 1987.

Morcrette, J.-J.: Radiation and Cloud Radiative Properties in the European Centre for Medium-Range Weather Forecasts Forecasting System, J. Geophys. Res., 96, 9121-9132, 1991.

Sander, S. P., Friedl, R. R., Golden, D. M., Kurylo, M. J., Moortgat, G. K., Keller-Rudek, H., Wine, P. H., Ravishankara, A. R., Kolb, C. E., Molina, M. J., Finlayson-Pitts, B. J., Huie, R. E., and Orkin, V. L.: Chemical kinetics and photochemical data for use in atmospheric studies, JPL Publication 06-2, 2006.

Solomon, S.: Stratospheric ozone depletion: A review of concepts and history, Rev. Geophys., 37, 275-316, doi:10.1029/1999RG900008, 1999.

Solomon, S., Garcia, R. R., Rowland, F. S., and Wuebbles, D. J.: On the depletion of Antarctic ozone, Nature, 321, 755-758, 1986.

Solomon, S., Portmann, R. W., Sasaki, T., Hofmann, D. J., and Thompson, D. W. J.: Four decades of ozonesonde measurements over Antarctica, J. Geophys. Res., 110, D21311, doi:10.1029/2005JD005917, 2005.

Vömel, H. and Diaz, K.: Ozone sonde cell current measurements and implications for observations of near-zero ozone concentrations in the tropical upper troposphere, Atmos. Meas. Tech., 3, 495-505, doi:10.5194/amt-3-495-2010, 2010.

von Hobe, M., Stroh, F., Beckers, H., Benter, T., and Willner, H.: The UV/Vis absorption spectrum of matrix-isolated dichlorine peroxide, $\mathrm{ClOOCl}$, Phys. Chem. Chem. Phys., 11, 1571-1580, doi:10.1039/b814373k, 2009.

Walter, R.: CLaMS-Simulation des stratosphärischen Ozonabbaus im antarktischen Winter 2003, Diplomarbeit, Technische Universität Bergakademie Freiberg Germany, , 2005.

WMO: Scientific assessment of ozone depletion: 2010, Global Ozone Research and Monitoring Project-Report No. 52, Geneva, Switzerland, 2011.

Zhong, W. and Haigh, J. D.: Improved Broadband Emissivity Parameterization for Water Vapor Cooling Rate Calculations, J. Atmos. Sci., 52, 124-138, 1995. 